\title{
Towards flexibility: Metal free plastic cathodes for Dye sensitized solar cells
}

\author{
Shahzada Ahmad, ${ }^{a, b}$ Elisa Dellorto, ${ }^{\mathrm{a}}$ Jun-Ho Yum, ${ }^{\mathrm{a} *}$ Florian Kessler, ${ }^{\mathrm{a}}$ Mohammad K. Nazeeruddin, ${ }^{\mathrm{a}}$ and \\ Michael Grätzel $^{\mathbf{a}^{*}}$
}

${ }_{5}$ Received (in $\left.X X X, X X X\right) X$ th $X X X X X X X X X 20 X X$, Accepted $X$ th $X X X X X X X X X 20 X X$
DOI: 10.1039/b000000x

We report herewith lightweight, and low cost dye-sensitized solar cells employing an all plastic metal free cathode consisting of poly(3,4-ethylenedioxythiophene).

10 Renewable sources of energy especially conversion of solar energy into electricity is now being regarded as green and clean. Among the various technologies, dye-sensitized solar cell (DSSC, called Grätzel cell) is one of the promising alternative, which is being probed both by scientists as well as industry because of 15 low-cost fabrication process. ${ }^{1,2}$ The ability of being designed as flexible device, high efficiency under low and diffuse light further adds to its advantage compared to the other PV technologies. Significant efforts have focused on the development of new sensitizers, semiconductor photoanodes and redox couples 20 to obtain efficient devices, ${ }^{3,4}$ however not much emphasis has been given to find alternate current collector which may drastically reduce the cost of the dye sensitized solar cells. Up to now transparent conducting oxides (TCO) coated glasses are mainly used as a charge collector in DSSCs, which has a major 25 share of cost in fabrication (US $\$ 8-12 / \mathrm{m}^{2}$ on GW scale). In order to make DSSCs commercially viable (US $\$<20 / \mathrm{m}^{2}$ ), one glass substrate needs to be replaced. ${ }^{1}$ The limited resources, high cost of indium, brittleness and the high energy treatment during deposition process are making TCO coated glass un-economical 30 and alternatives are being sought by replacing it with doped $\mathrm{ZnO}$ coatings or metal grids. ${ }^{5-8}$ Further to realize the low-cost cells the typically used Pt-based catalysts that constitute the counterelectrodes of DSSCs due to numerous reason. Therefore it is paramount to develop TCO and Pt free new counter electrode 35 using materials that are cheaper and are capable of yielding comparable efficiency and device stability. Carbon based materials are envisioned as alternative to $\mathrm{Pt}$ as they are inexpensive, have low electrical resistance and shows electrocatalytic activity for the reduction of triiodide. Carbon nanotube / 40 graphene conductive coatings are also being probed as a possible replacement, posses high optical transparency along with low electrical resistance compare to TCO glasses. ${ }^{9}$ Conducting polymers are being exploited as an easy alternative for TCO coatings applications. Typically the conductivity is lower for 45 conducting polymers than of inorganic materials, but having the advantage of being flexible, less expensive and more environmentally friendly in processing and manufacture.
Poly(3,4-ethylenedioxythiophene) (PEDOT) is extensively exploited owing to its relatively high conductivity, low band gap $50(1.6 \mathrm{eV})$ excellent electrochemical and environmental stability, and higher transmittance in the visible spectrum,.$^{10-12}$, which can be utilized to rivial TCO coatings. Thus the high transmittance of the films opens the roads with potential applications in powerproducing windows or metal foil supported DSSCs. The PEDOT 55 coated cathode has been successfully demonstrated as an alternative for Pt catalysts, ${ }^{11,13,14}$ further using ionic liquids the microstructure can be altered to produce grains with diameters in the nanometer scale, resulting in increased hardness and electrocatalytic activity of PEDOT. Recently in situ chemical ${ }_{60}$ polymerization process has been utilized directly on the glass for the fabrication of TCO free DSSCs,${ }^{15}$ however these films suffer from very low adherence and can easily peel off from the substrate. Here in as a proof of concept we report the fabrication of metal free DSSCs cathode on plastic substrates i.e. 65 electropolymerized PEDOT (e-PEDOT)-on-PEDOT-PET substrates. The use of flexible DSSCs may allow for a reel-to-reel mass production and are considered as a suitable system for electronics-integrated lightweight photovoltaics. ${ }^{16,17}$ We believe that acceptable photovoltaic (PV) values could be obtained, with 70 fine-tuning and further optimization.

Table 1 summarize the photovoltaic properties obtained using D21L6 dye ${ }^{18}$ (structure in supporting info Fig. 1a) on a TCO free cathode and comparing it with reference platinized TCO coatings. The large difference in efficiency is due to the high resistance of ${ }_{75}$ PEDOT film, which resulted in reduced current density and fill factor $(F F)$, especially at full sun illumination intensity. In order to reduce the resistance, additional layers of PEDOT was deposited by electropolymerization (hereafter called as "ePEDOT"), this resulted in additional bluish coating on PEDOT 80 substrate itself. The high resistivity of PEDOT compared to TCO coatings lead to large voltage drop during electropolymerization and thus require higher current density. Table 1 shows the double layer PEDOT deposition increases current density and $F F$, which was possible by minimizing the sheet resistance and as a result 85 improving the conductivity. The current was eventually improved from 4.6 to $9.3 \mathrm{~mA} / \mathrm{cm}^{2}$ and attained to $80 \%$ of reference platinized cathode value with a power conversion efficiency of $1.94 \%$ at full sun. Still high resistivity of PEDOT was placing limitation in charge collection and limiting the current density. To 
achieve the enhanced PV parameters these films were treated with ethylene glycol to increase the charge transport properties of the PEDOT. The conductivity of PEDOT can be increased by many folds with the post treatment of ethylene glycol. ${ }^{8}$ After 5 treatment with ethylene glycol the device shows improvement in $F F$ and in the photo-current values most likely due to lower series resistance. Moreover, the good adherence of the polymer layers to the substrates gave reproducible device performance. The $V_{\mathrm{oc}}$ of the polymer cathode device is almost similar to the platinized 10 cathode while the $F F$ values are relatively low for polymer cathode. The obtained low $F F$ is due to the high series resistance and the charge transfer resistance leading to loss of current and thus power conversion efficiency. .

Table 1: Photovoltaic results obtained DSSC employing D21L6 dye on a 15 single layer $\mathrm{TiO}_{2}$ film having $\sim 5.8 \mu \mathrm{m}, \mathrm{Z} 960$ as an electrolyte and counter electrodes: Pt on FTO, PEDOT and e-PEDOT double layers.

\begin{tabular}{c|c|ccc}
\hline & & 0.095 Sun & 0.51 Sun & 1 Sun \\
\hline \multirow{3}{*}{ FTO/ Pt } & $\mathrm{V}_{\mathrm{OC}}(\mathrm{mV})$ & 673 & 722 & 738 \\
& $\mathrm{~J}_{\mathrm{SC}}\left(\mathrm{mA} / \mathrm{cm}^{2}\right)$ & 1.14 & 5.98 & 11.55 \\
& $\mathrm{FF}$ & 0.732 & 0.711 & 0.680 \\
& $\eta(\%)$ & 5.90 & 6.05 & 5.80 \\
\hline \multirow{3}{*}{ PEDOT } & $\mathrm{V}_{\mathrm{OC}}(\mathrm{mV})$ & 663 & 707 & 721 \\
& $\mathrm{~J}_{\mathrm{SC}}\left(\mathrm{mA} / \mathrm{cm}^{2}\right)$ & 0.98 & 4.08 & 4.61 \\
& $\mathrm{FF}$ & 0.60 & 0.28 & 0.26 \\
& $\eta(\%)$ & 4.09 & 1.57 & 0.88 \\
\hline \multirow{3}{*}{ e-PEDOT } & $\mathrm{V}_{\mathrm{OC}}(\mathrm{mV})$ & 644 & 695 & 711 \\
& $\mathrm{~J}_{\mathrm{SC}}\left(\mathrm{mA} / \mathrm{cm}^{2}\right)$ & 1.05 & 5.43 & 9.27 \\
& $\mathrm{FF}$ & 0.63 & 0.40 & 0.30 \\
& $\eta(\%)$ & 4.51 & 2.98 & 1.94 \\
\hline
\end{tabular}

The second step concerned the possibility to increase current 20 density replacing a dye and an electrolyte. Recently ${ }^{3,20}$ a dye called Y123 (structure in supporting info. Fig. 1b) has shown very promising $\mathrm{PV}$ performance particularly with cobalt complexes, both $\left[\mathrm{Co}(\mathrm{bpy})_{3}\right]^{3+/ 2+}$ and $\left[\mathrm{Co}(\mathrm{bpy}-\mathrm{pz})_{2}\right]^{3+/ 2+}$ used instead of $\mathrm{I}_{3}{ }^{-} / \mathrm{I}^{-}$as a redox couple. In addition, the high charge 25 transfer resistance with $\mathrm{Pt}$ cathode turned out to be able to be reduced by replacing with a conduction polymer cathode. ${ }^{3}$ Table 2 summarize the PV results with $\mathrm{Y} 123$ sensitized $\mathrm{TiO}_{2}$ film in conjunction with cobalt electrolytes comparing with $\mathrm{I}_{3}{ }^{-} / \mathrm{I}^{-}$redox couple. Open circuit voltage $\left(V_{o c} s\right)$ was mainly improved: $\sim 150$ $30 \mathrm{mV}$ with $\left[\mathrm{Co}(\mathrm{bpy})_{3}\right]^{3+/ 2+}$ and $\sim 260 \mathrm{mV}$ with $\left[\mathrm{Co}(\mathrm{bpy}-\mathrm{pz})_{2}\right]^{3+/ 2+}$, respectively when compared to the $\mathrm{I}_{3}{ }^{-} / \mathrm{I}^{-}$redox couple. The higher $V_{o c} \mathrm{~s}$ are associated with the higher redox potentials of the cobalt redox couples. Improvement in fill factor is plausibly ascribed to low charge transfer resistance with conducting polymer, which is 35 in agreement with previous study. ${ }^{3}$ In consequence of PV results, the best result, $4.22 \%$ at full sun (Fig.1) was achieved using a $\left[\mathrm{Co}(\mathrm{bpy})_{3}\right]^{3+/ 2+}$ redox couple while $3.96 \%$ was achieved by $\left[\mathrm{Co}(\mathrm{bpy}-\mathrm{pz})_{2}\right]^{3+/ 2+}$. It is noteworthy that the cells with $\left[\mathrm{Co}(\mathrm{bpy})_{3}\right]^{3+/ 2+}$ and $\left[\mathrm{Co}(\mathrm{bpy}-\mathrm{pz})_{2}\right]^{3+/ 2+}$ produced efficiencies close 40 to 7 and $6 \%$, respectively, under low intensities i.e. 0.095 sun. Although there was enhancement in the fill factor by employing cobalt shuttle, the values are still lower than $\sim 0.70$ achieved with $\mathrm{Pt} / \mathrm{FTO}$, which is most likely associated with high series resistance. This implies that decreasing the series resistance can 45 further enhance PV performance.
Table 2: Photovoltaic results obtained DSSC employing Y123 dye on a single layer $\mathrm{TiO}_{2}$ film having $\sim 6.5 \mu \mathrm{m}$, e-PEDOT and electrolyte: $\mathrm{I}_{3}{ }^{-} / \mathrm{I}^{-}$ $(\mathrm{JH} 34),\left[\mathrm{Co}(\mathrm{bpy}-\mathrm{pz})_{2}\right]^{3+/ 2+}(\mathrm{JH} 70)$, and $\left[\mathrm{Co}(\mathrm{bpy})_{3}\right]^{3+/ 2+}(\mathrm{JH} 180)$.

\begin{tabular}{c|c|ccc}
\hline & & & & \\
\hline \multirow{5}{*}{$\mathrm{JH} 34$} & & 0.095 Sun & 0.51 Sun & 1 Sun \\
& $\mathrm{V}_{\mathrm{OC}}(\mathrm{mV})$ & 597 & 660 & 680 \\
& $\mathrm{~J}_{\mathrm{SC}}\left(\mathrm{mA} / \mathrm{cm}^{2}\right)$ & 0.98 & 5.15 & 9.85 \\
& $\mathrm{FF}$ & 0.65 & 0.46 & 0.34 \\
& $\eta(\%)$ & 4.19 & 3.23 & 2.38 \\
\hline \multirow{3}{*}{$\mathrm{JH70}$} & $\mathrm{V}_{\mathrm{OC}}(\mathrm{mV})$ & 865 & 924 & 942 \\
& $\mathrm{~J}_{\mathrm{SC}}\left(\mathrm{mA} / \mathrm{cm}^{2}\right)$ & 1.04 & 5.46 & 10.38 \\
& $\mathrm{FF}$ & 0.69 & 0.53 & 0.39 \\
& $\eta(\%)$ & 6.86 & 5.46 & 3.96 \\
\hline \multirow{5}{*}{$\mathrm{JH} 180$} & $\mathrm{~V}_{\mathrm{OC}}(\mathrm{mV})$ & 724 & 801 & 830 \\
& $\mathrm{~J}_{\mathrm{SC}}\left(\mathrm{mA} / \mathrm{cm}^{2}\right)$ & 1.08 & 5.67 & 10.92 \\
& $\mathrm{FF}$ & 0.68 & 0.55 & 0.47 \\
& $\eta(\%)$ & 5.62 & 4.88 & 4.22 \\
\hline
\end{tabular}

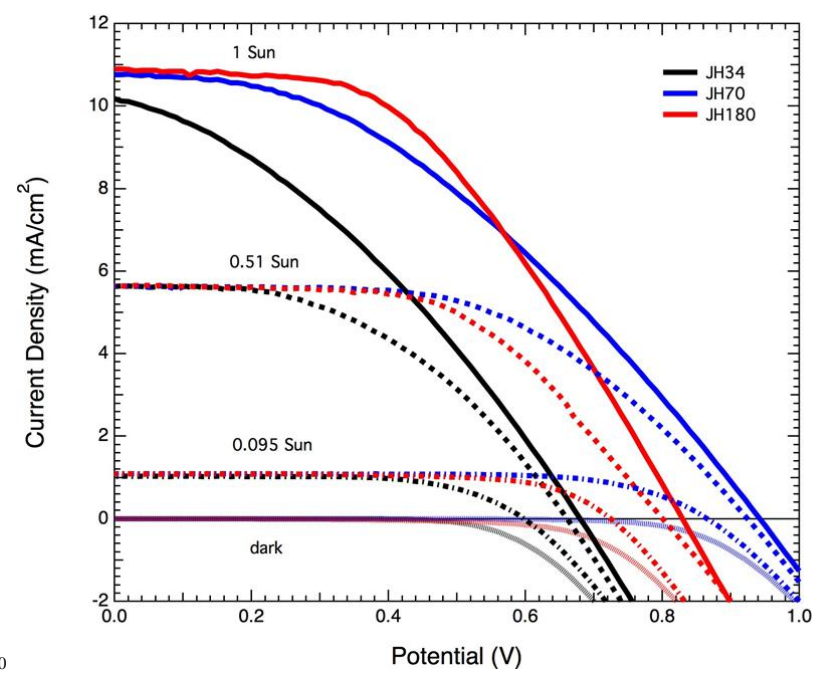

Fig. 1: The J-V curves of DSSCs fabricated with PEDOT as shown in table 1. DSSCs employ $\mathrm{Y} 123$ dye on a single layer $\mathrm{TiO}_{2}$ film having $\sim 6.5$ $\mu \mathrm{m}$, PEDOT double layers, and electrolyte: $\mathrm{I}_{3}{ }^{-} / \mathrm{I}^{-}$(JH34) (black lines), $\left[\mathrm{Co}(\mathrm{bpy}-\mathrm{pz})_{2}\right]^{3+/ 2+}(\mathrm{JH} 70)$ (blue lines), and $\left[\mathrm{Co}(\mathrm{bpy})_{3}\right]^{3+2+}$ (JH180) (red 55 lines). All solid, dashed, and dash-dotted curves indicate the $J$ - $V$ curves at 1, 0.51, and 0.095 Sun, respectively while all dotted lines indicate dark currents.

The $J_{s c}$ and $V_{o c}$ of these devices shows notable decrease when the light intensity was lowered, while the $F F$ increases and high ${ }_{60}$ efficiencies were obtained at 0.1 Sun. The current density increases in linear proportion to light intensity indicating that it is not limited by charge transport. The best internal photon-toelectron-conversion efficiency (IPCE) of the device employing Y123 sensitizer, $\left[\mathrm{Co}(\mathrm{bpy})_{3}\right]^{3+/ 2+}$ redox shuttle, and PEDOT as a 65 cathode shows broad IPCE almost plateau like in UV-Vis region from with high IPCE maxima $>60 \%$ (Fig.2), without significantly decreasing the optical transmission. These metal free DSSCs cathode exhibits comparable quantum efficiency over the whole spectrum range.

${ }_{70}$ We have shown the feasibility of metal free cathode made up of all plastic (e-PEDOT-PEDOT-PET). Iodine free DSSCs composed of noncorrosive cobalt (III/II) redox shuttle were also 


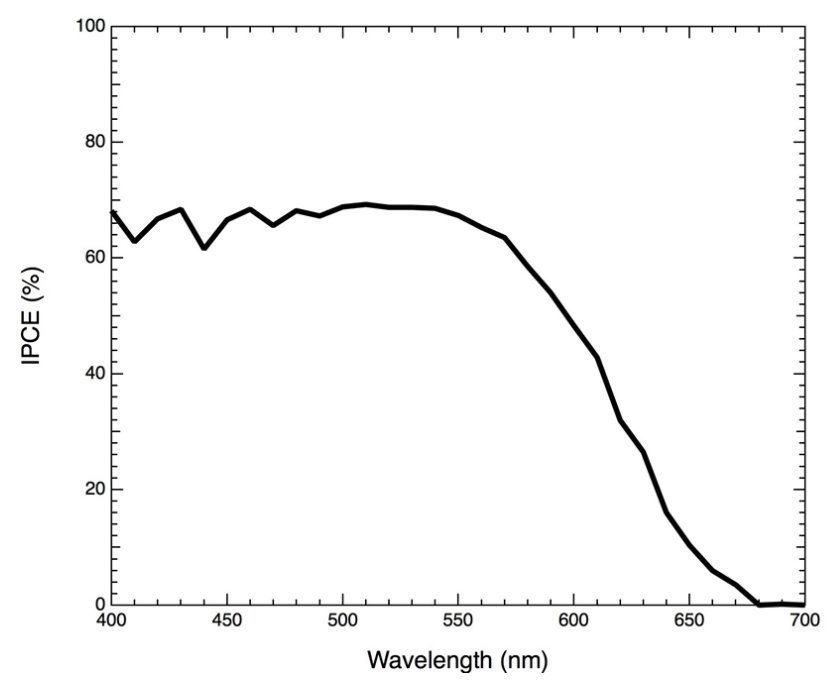

Fig. 2: The IPCE as function of wavelength of monochromatic light for DSSCs fabricated with PEDOT based cathode using cobalt redox couple..

5 investigated and delivered better results than the classical iodide electrolytes. Electropolymerized PEDOT layers deposited on PEDOT coated PET surface acts as both charge collector and as efficient electro-catalysts. A cell performance of $4.22 \%$ can be achieved at full sun, which is $27 \%$ less than standard values of ${ }_{10}$ platinized TCO coated electrodes, but at the fraction of its cost. Together with metal foil based photo anode these newly developed cathode will pave way for reel-to-reel DSSCs fabrication. We believe that with further modification this process can be optimized to give equivalent results and the reported 15 system shows great potential for cost effective DSSCs fabrication.

We gratefully acknowledges Agfa, Prof. Lichen Sun (KTH), and NEC (Japan) for their geneorsity in providing the PEDOT substrates, D21L6, 20 and Y123, respectively. The authors thank Mr. Pascal Comte for the $\mathrm{TiO}_{2}$ paste preparation. S.A. acknowledges to the Alexander von HumboldtFoundation and Prof. H. J. Butt for their support. This work was partially funded by the European Community's Seventh Framework Program (FP7/2007-2013) under grant agreement no 246124 of the "SANS" 25 project and "ESCORT" agreement no. ENERGY-261920. J.-H.Y. acknowledges the support from the Korea Foundation for International Cooperation in Science and Technology through the Global Research Lab.

${ }^{a}$ Laboratory of Photonics and Interfaces, Department de Chimie, Ecole 30 Polytechnique Federale de Lausanne, CH-1015 Lausanne, Switzerland; E-mail: michael.graetzel@epfl.ch, junho.yum@epfl.ch

${ }^{b}$ Max Planck Institute for Polymer Research, Ackermannweg 10

D-55138 Mainz, Germany; E-mail: ahmad@mpip-mainz.mpg.de

† Electronic Supplementary Information (ESI) available: [Synthesis,

35 device fabrication as well as electro-chemical activity]. See DOI: $10.1039 / \mathrm{b} 000000 \mathrm{x} /$

\section{Notes and references}

1. B. E. Hardin, H. J. Snaith and M. D. McGehee, Nature Photon., 2012, 6,162 .

40 2. A. Hagfeldt, G. Boschloo, L. Sun, L. Kloo and H. Pettersson, Chem. Rev., 2010, 110, 6595.

3. J.-H. Yum, E. Baranoff, F. Kessler, T. Moehl, S. Ahmad, T. Bessho, A. Marchioro, E. Ghadiri, J.-E. Moser, C. Yi, M. K. Nazeeruddin and M. Grätzel, Nature Commun., 2012, 3, 631.

45 4. J. Burschka, V. Brault, S. Ahmad, L. Breau, M. K. Nazeeruddin, B. Marsan, S. M. Zakeeruddin and M. Grätzel, Energy Environ. Sci.,
2012, 5, 6089; H. Tian, E. Gabrielsson, Z. Yu, A. Hagfeldt, L. Kloo and L. Sun, Chem. Commun., 2011, 47, 10124

5. A. De Sio, K. Chakanga, O. Sergeev, K.v. Maydell, J. Parisi and E. vonHauff, Sol. Energy Mater. Sol. Cells, 2012, 98, 52-56.

6. Y. Fu, Z. Lv, S. Hou, H. Wu, D. Wang, C. Zhang and D. Zou, Adv. Energy Mater., 2012, 2, 37-41

7. Y. Galagan, B. Zimmermann, E. W. C. Coenen, M. Jørgensen, D. M. Tanenbaum, F. C. Krebs, H. Gorter, S. Sabik, L. H. Slooff, S.C.

55 Veenstra, J. M. Kroon and R. Andriessen, Adv. Energy Mater., 2012, $2,103-110$.

8. Y. H. Kim, C. Sachse, M. L. Machala, C. May, L. M. Meskamp and K. Leo, Adv. Funct. Mater., 2011, 21, 106-1081

9. H. Zhu, J. Wei, K. Wang and Dehai Wu, Sol. Energy Mater. Sol. Cells, 2009, 93, 1461-1470.

10. P. M. Sirimanne, B. W.-Jensen, H. C. Weerasinghe and Y.-B. Cheng, Thin solid films, 2010, 518, 2871-2875.

11. K. Manseki, W. Jarenboon, Y. Youhai, K-J. Jiang, K. Suzuki, N. Masaki, Y. Kim, J. Xia and S. Yanagida, Chem. Commun., 2011, 47, 3120-3122.

12. S. Ahmad, J.-H. Yum, Z. Xianxi, M. Grätzel, H.-J. Butt and M. K. Nazeeruddin, J. Mater. Chem. 2010, 20, 1654-1658; S. Ahmad, J.-H. Yum, H.-J. Butt, M. K. Nazeeruddin and M. Grätzel, Chem. Phys Chem., 2010, 11, 2814

70 13. V. C. Tung, J. Kim, L. J. Cote, and J. Huang, J. Am. Chem. Soc.,2011, 133, 9262-9265.

14. J. M. Pringle, V. Armel and D. R. MacFarlane, Chem. Commun., 2010, 46, 5367-5369.

15. K. S. Lee, H. K. Lee, D.H. Wang, N. G. Park, J.Y. Lee, O. O. Park and J. H. Park, Chem. Commun., 2010, 46,4505-4507.

16. S. Ito, N.-L. C. Ha, G. Rothenberger, P. Liska, P. Comte, S. M. Zakeeruddin, P. Péchy, M. K. Nazeeruddin and M. Grätzel, Chem. Commun., 2006, 4004.

17. H.-G. Yun, B.-S. Bae, and M. G. Kang, Adv. Energy Mater., 2011, 1, 337-342.

18. J.-H. Yum, D. P. Hagberg, S.-J. Moon, K. M. Karlsson, T. Marinado, L. Sun, A. Hagfeldt, M. K. Nazeeruddin, and M. Grätzel, Angew. Chem. Int. Ed., 2009, 48, $1576-1580$.

19. Y.Shi, S.-C- Luo, W. Fang, K. Zhang, E. M. Ali, F.Y.C. Boey, J. Y 85 Ying, J. Wang, H.-H Yu, L.-J. Li, Org. Electron., 2008, 9, 859-863.

20. H. N. Tsao, C. Yi, T. Moehl, J-H. Yum, S. M. Zakeeruddin, M. K. Nazeeruddin and M. Grätzel, ChemSusChem, 2011, 4, 591-594. 


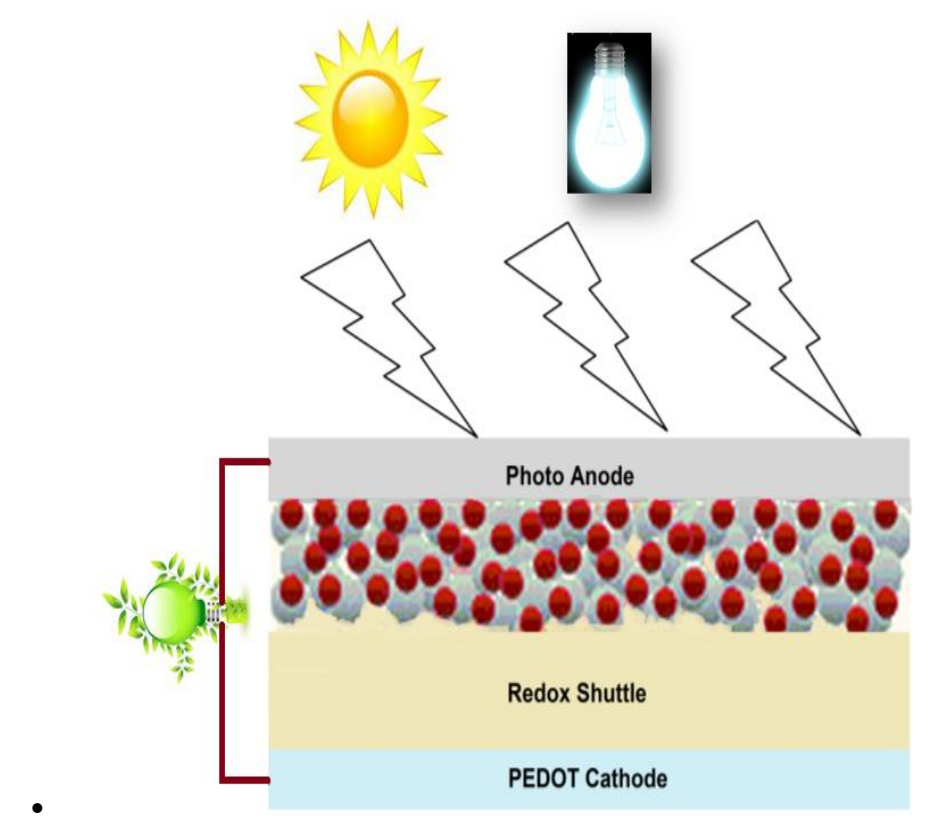

